P-ISSN: 2774-4574; E-ISSN: 2774-4582

TRILOGI, 1(2), Sept-Des 2020 (35-45)

@2020 Lembaga Penerbitan, Penelitian, dan Pengabdian kepada Masyarakat (LP3M)

Universitas Nurul Jadid Paiton Probolinggo

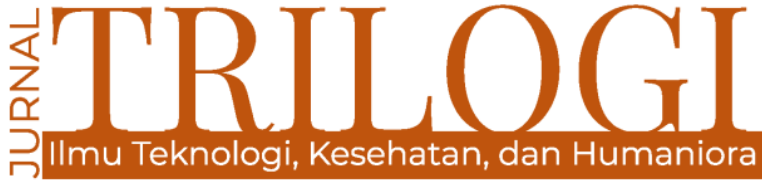

DOI: https://doi.org/

\title{
MANAJEMEN KLUSTERISASI PASAR: \\ Penerapan Segmentasi Pelanggan Berbasis Metode Self- Organizing Map (SOM) di CV Karunia Probolinggo
}

\author{
Abu Tholib \\ Teknik Informatika, Universitas Nurul Jadid Probolinggo, Indonesia \\ ebuenje@gmail.com
}

\begin{abstract}
Sebagai salah satu distributor yang bergerak di bidang penjualan dan distribusi kosmetik, CV Karunia bertugas melayani pelanggan yang telah melakukan pemesanan, sehingga setiap pengiriman pesanan harus tercatat dengan baik. Dengan mengelompokkan pelanggan sesuai wilayah dan pesanan, distributor lebih mudah mengetahui wilayah mana dan pelanggan siapa dengan jumlah pesanan paling banyak. Oleh karena itu, CV Karunia harus mempunyai strategi pemetaan pelanggan, misalnya dengan menggunakan metode SOM (Self Organizing Maps) yang bertujuan untuk memudahkan upaya pemasaran dan pengelompokan pelanggan sesuai dengan keinginan dan kebiasaan pelanggan, agar memperoleh hasil yang maksimal. Melalui metode SOM ini, pengambilan keputusan pelanggan dan optimalisasi proses layanan pelanggan bisa dilakukan dengan baik.
\end{abstract}

Keywords: segmentasi pelanggan; metode SOM; strategi pemasaran

\begin{abstract}
Abstrak
As one of the distributors engaged in the sale and distribution of cosmetics, CV Karunia is in charge of serving customers who have placed an order, so that each order delivery must be recorded properly. By grouping customers according to regions and orders, it will be easier for distributors to know which regions and whose customers have the largest number of orders. Therefore, CV Karunia must have a customer mapping strategy, for example by using the SOM (Self Organizing Maps) method which aims to facilitate marketing efforts and customer grouping according to customer desires and habits, in order to obtain maximum results. Through this SOM method, customer decision making and optimization of the customer service process can be done well.
\end{abstract}

Katakunci: customer segmentation; metode SOM; marketing strategi 


\section{Pendahuluan}

Dunia usaha memegang peranan penting dalam pembangunan, baik yang diusahakan oleh pemerintah melalui Badan Usaha Milik Negara (BUMN) maupun yang dilaksanakan oleh pihak swasta. Sukses suatu perusahaan hanya mampu dicapai dengan manajemen yang baik, yaitu manajemen yang mampu mempertahankan kontinuitas perusahaan dengan memperoleh laba yang maksimal karena pada dasarnya tujuan perusahaan adalah memaksimalkan kemakmuran perusahaan itu sendiri. Keberhasilan perusahaan dalam mempertahankan kontinuitas atau kelangsungan hidupnya bisa dicapai bila perusahaan tersebut memiliki pandangan ke luar dan selalu memonitor keadaan lingkungan yang berubah-ubah serta menyesuaikan usaha pemasarannya berdasarkan peluang-peluang yang dimiliki.

Dalam usaha mencapai kesuksesan tersebut, peranan manajer dalam memilih dan merencanakan strategi pemasaran sangat penting guna memenuhi kebutuhan konsumen. Saat mengembangkan strategi pemasaran, manajer harus mempertimbangkan untuk tidak hanya memenuhi kebutuhan konsumen, melainkan juga mempertimbangkan posisi industri perusahaan yang bersangkutan dibandingkan perusahaan pesaing (Yuliana, 2013). Oleh karena itu, manajer pemasaran harus merancang strategi pemasaran yang kompetitif dan sepadan dengan posisi dan sumber daya pesaing serta menyesuaikan strategi-strategi tersebut dengan kondisi persaingan secara berkesinambungan.

Penelitian di bidang segmentasi pelanggan telah banyak dilakukan. Hal ini dapat diketahui dari jumlah jurnal yang dipublikasikan pada IEEE. Pada tanggal 25 Juni 2013 dengan kata kunci "customer segmentation" didapatkan data penelitian berjumlah 271 artikel. Shin dan Sohn (2004) dalam penelitiannya menggunakan algoritma KMeans, SOM, dan Fuzzy C-Means untuk mencari segmentasi konsumen pasar modal berdasarkan nilai potensialnya, yaitu berdasarkan total nilai transaksi yang dilakukan dalam periode tiga bulan. Dari hasil perbandingan terhadap ketiga metode tersebut, algoritma SOM memiliki hasil segmentasi yang lebih akurat.

Suatu organisasi yang memutuskan untuk beroperasi di salah satu pasar konsumsi, mengakui bahwa pada dasarnya organisasi tersebut tidak dapat melayani semua pelanggan. Hal ini dikarenakan jumlah pelanggan terlalu besar dan wilayahnya terlalu luas dengan beraneka ragam kebutuhan dan keinginan serta kebiasaan dalam membeli sedangkan para pelanggan menuntut untuk dilayani secara efektif dan efisien.

Untuk itu, salah satu upaya yang dilakukan oleh perusahaan agar dapat tetap berada dalam posisi yang efektif dalam melayani segmen-segmen pelanggan yang memadai dari pasar yang dituju adalah dengan menetapkan segmentasi pelanggan. Segmentasi pelanggan pada dasarnya merupakan suatu cara untuk membedakan pelanggan menurut beberapa karakter dan tingkah laku (Adiana et al, 2018). Menyadari pentingnya penerapan segmentasi pelanggan, maka obyek yang akan diteliti pada penelitian ini adalah CV. Karunia, yakni sebuah perusahaan yang bergerak pada bidang industri kosmetik, CV. Karunia dikenal sebagai salah satu produsen kosmetik besar di kawasan Kota Probolinggo.

Sebagai gambaran awal, berikut ini adalah perkembangan penjualan CV. Karunia di kawasan Kota Probolinggo untuk semua kosmetik dari tahun 2013 sampai dengan 2018:

Tabel 1. Perkembangan Penjualan Kosmetik di Kawasan Probolinggo pada CV. Karunia Tahun 2013-2017

\begin{tabular}{c|c|c}
\hline Tahun & $\begin{array}{c}\text { Unit } \\
\text { Penjualan } \\
\text { kosmetik }\end{array}$ & $\begin{array}{c}\text { Perkembangan } \\
\text { penjualan (\%) }\end{array}$ \\
\hline 2013 & 258.743 & \\
\hline 2014 & 281.771 & 8,9 \\
\hline 2015 & 280.736 & 8,5 \\
\hline 2016 & 283.841 & 9,7 \\
\hline 2017 & 287.722 & 11,2 \\
\hline Total & 1.392 .813 & 38,3 \\
\hline Rata-rata & 278.562 & 9,57 \\
\hline
\end{tabular}

Sumber: CV. Karunia, 2018 
Berdasarkan data di atas, total volume penjualan kosmetik selama lima tahun terakhir adalah 1.392.813 dengan tingkat pertumbuhan penjualan rata-rata sebesar 9,57 \% setiap tahunnya (Faizah et al, 2019). Untuk mengantisipasi persaingan yang semakin ketat serta untuk lebih meningkatkan volume penjualan maka upaya yang dilakukan oleh perusahaan adalah dengan menetapkan segmentasi pelanggan berdasarkan geografis yaitu pengelompokkan pelanggan menurut daerah pemasarannya. Tujuan perusahaan menerapkan segmentasi pelanggan berdasarkan geografis adalah untuk lebih memfokuskan pemasaran pada suatu wilayah sehingga perusahaan dapat menetapkan prioritas dalam melayani pelanggan secara maksimal. Wilayah yang ditentukan dalam segmentasi pelanggan oleh CV. Karunia Kota Probolinggo, Kabupaten Probolinggo.

Dalam upaya untuk menjaga daya saing CV. Karunia, muncul isu menarik yang terangkat dari suatu fenomena yang terjadi di awal milenium bahwa penjualan kosmetik belum sesuai dengan target perusahaan sehingga perusahaan berkeinginan untuk melakukan evaluasi strategi segmentasi pelanggan dalam penjualan kosmetik. Hal inilah yang mendasari penulis untuk mengadakan suatu penelitian dan menganalisisnya guna menjelaskan efektivitas segmentasi pelanggan yang dilakukan oleh perusahaan khususnya dalam 5 (lima) tahun terakhir. Dalam kegiatan penilitian ini, penulis memilih judul: "Penerapan Segmentasi Pelanggan Berbasis Metode SelfOrganizing Map (SOM) di CV Karunia Probolinggo."

Penelitian ini bertujuan sebagai bahan acuan dan pertimbangan bagi pihak perusahaan dalam mengambil langkah-langkah kebijakan mengenai segmentasi pelanggan; mempermudah strategi pemasaran untuk memenuhi kebutuhan konsumen sesuai keinginan dan kebiasaan dalam membeli; untuk pembaca, dapat menambah wawasan dan ilmu pengetahuan mengenai pentingnya penerapan segmentasi pelanggan terhadap pemasaran. Dengan penelitian ini diharapkan proses penjualan di CV. Karunia ini menjadi lebih mudah cepat dan akurat.

\section{Metode}

Rancangan atau desain penelitian dalam arti sempit dimaknai sebagai suatu proses pengumpulan dan analisis data penelitian. Di bawah ini rancangan penelitian yang dibuat agar pelaksanaan penelitian berjalan dengan baik:

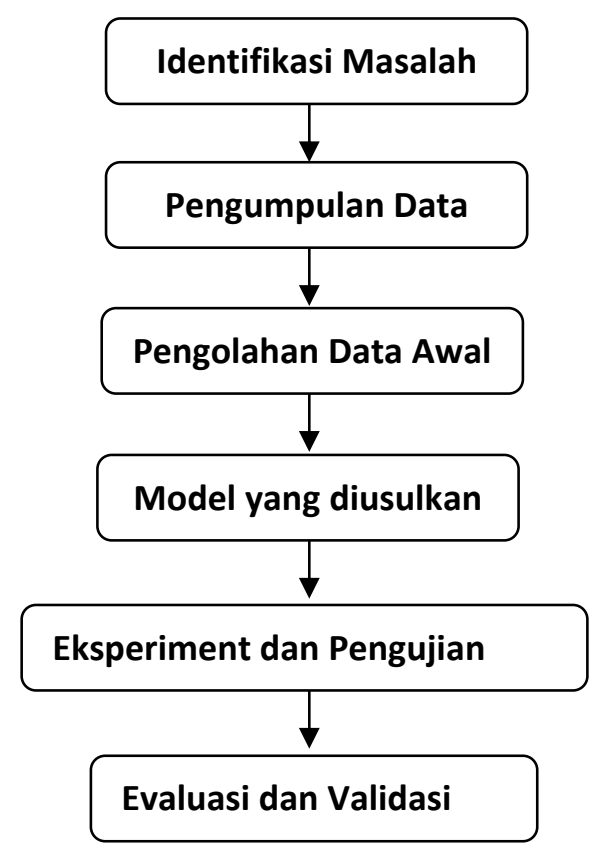

Gambar 1. Rancangan Penelitian

Pada penelitian kali ini yang digunakan adalah penelitian eksperimen. Penelitian eksperimen melibatkan penyelidikan perlakuan pada parameter/variabel tergantung dari penelitinya dan menggunakan tes yang dikendalikan oleh si peneliti itu sendiri (Zeniarja \& Luthfiarta, 2015). Dalam penelitian eksperimen digunakan spesifikasi software dan hardware sebagai alat bantu dalam penelitian pada Tabel 3.1:

Tabel 1. Spesifikasi Hardware dan Software

\begin{tabular}{ll}
\hline \multicolumn{1}{c}{ Software } & \multicolumn{1}{c}{ Hardware } \\
\hline Sistem Operasi: & CPU: Intel Pentium \\
Windows 7 & Core i3 \\
\hline Data Mining: Rapid & Memory: 2 GB \\
\cline { 2 - 2 } Miner & Hardisk: 250 GB \\
\hline
\end{tabular}

Pada metode penelitian eksperimen, terdapat beberapa tahapan penelitian yang dilakukan seperti berikut:

1. Pengumpulan data

Pada tahap ini ditentukan data yang akan diproses. Mencari data yang tersedia, memperoleh data tambahan yang dibutuhkan, mengintegrasikan semua data kedalam data set, termasuk variabel yang diperlukan dalam proses. 


\section{Pengolahan awal data}

Ditahap ini dilakukan penyeleksian data, data dibersihkan dan ditransformasikan kebentuk yang diinginkan sehingga dapat dilakukan persiapan dalam pembuatan model.

3. Model yang diusulkan

Pada tahap ini data dianalisis, dikelompokan variabel mana yang berhubungan dengan satu sama lainnya. Setelah data dianalisis lalu diterapkan modelmodel yang sesuai dengan jenis data. Pembagian data kedalam data latihan (training data) dan data uji (testing data) juga diperlukan untuk pembuatan model.

4. Eksperimen dan pengujian model

Pada tahap ini model yang diusulkan akan diuji untuk melihat hasil berupa rule yang akan dimanfaatkan dalam pengambilan keputusan.

5. Evaluasi dan validasi hasil

Pada tahap ini dilakukan evaluasi terhadap model yang ditetapkan untuk mengetahui tingkat keakurasian model

\section{Diskusi dan Pembahasan}

Subab ini akan menjelaskan beberapa konsep penting yang akan dibahas terkait dengan metode SOM sebagai perangkat segmentasi pasar, dan pembahasannya sesuai dengan metodologi penelitian yang telah dijelaskan pada bab subbab sebelumnya

\subsection{Customer Relationship}

\section{Management}

CRM diartikan sebagai satu kesatuan penjualan, pemasaran dan strategi pelayanan yang mencegah terjadinya aktivitas pekerjaan yang tidak terkoordinasi antar bagian dengan baik dan itu tergantung pada aksi - aksi perusahaan yang terkoordinasi (Kalakota, 2001). Di dalam pengelolaan hubungan pelanggan terdapat empat hal yang menjadi fokus utama. Keempat hal tersebut yaitu customer identification, customer attraction, customer retention dan customer development.

\subsection{Segmentasi Pelanggan}

Don Pepper dan Martha Roger dalam bukunya Managing Customer Relationship : A Strategi Framework melakukan kategorisasi pelanggan sebagai berikut:

1. Most Valuble Customer (MVC), yaitu pelanggan dengan nilai paling tinggi bagi perusahaan. Merupakan pelanggan yang memberikan keuntungan terbesar bagi perusahaan.
2. Most Growable Customer, yaitu pelanggan yang tanpa disadari memiliki potensi besar.

3. Below Zeros, yaitu pelanggan yang memberikan keuntungan lebih sedikit daripada biaya untuk memberikan pelayanan.

4. Migrators, yaitu pelanggan yang berada pada posisi diantara below zeros dan most growable customer dan perlu dianalisis agar dapat diketahui kategori asalnya (Pepper. D \& Roger, M., 2001).

\subsection{Model RFI}

Model RFM diaplikasikan secara luas pada database pemasaran dan merupakan tool yang umum digunakan untuk membangun strategi pemasaran. (Wei, et al., 2010). RFM berdasarkan segmentasi pelanggan menghasilkan kemampuan segmentasi antara $75 \%$ sampai $85 \%$. (Hughes, 2000 ).

Berikut ini adalah penjelasan mengenai RFM menurut C.H. Cheng, Y.S Chen (2009):

1. Recency, yaitu kapan transaksi terakhir dilakukan

2. Frequency, tingkat keseringan pelanggan melakukan transaksi. Misalkan sekali transaksi tiap bulan, atau 2 kali dalam satu tahun

3. Monetary, besarnya nilai transaksi yang dilakukan.

\subsection{Data Mining}

Data mining adalah suatu istilah yang digunakan untuk menguraikan penemuan pengetahuan di dalam database.

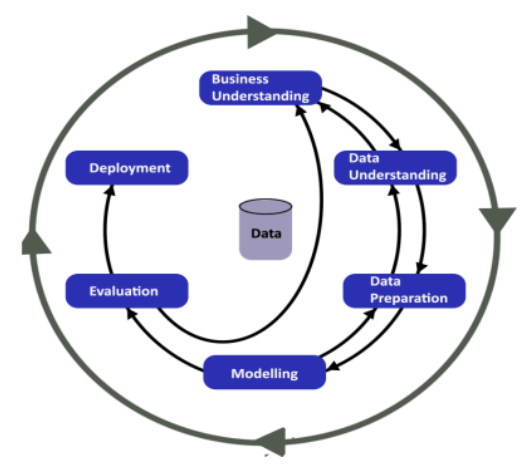

Gambar 2. Metode CRISP-DM (www.stellarconsulting.co.nz)

\subsection{Metode SOM}

Metode SOM adalah salah satu teknik lain untuk menganalisa data pada dimensi tinggi adalah dengan SOM (Self Organizing Feature Map). SOM dikembangkan Prof. Teuvo Kohonen (Finland) untuk memproyeksikan data ke 1 atau 2 dimensi, dengan mempertahankan 
topologi data tersebut (topological mapping) (Kuo et al, 2002). Data di ruang vektor berdimensi tinggi berdekatan, saat dipetakan ke ruang vektor $2 \mathrm{D}$, akan terletak pada lokasi yang berdekatan pula, vice versa.

\subsection{Metode CRISP-DM}

Rancangan tahapan penelitian mengacu pada enam tahap CRISP-DM, atau siklus hidup pengembangan data mining sebagai framework dari proyek data mining (Chapman et al, 2000). 1. Bussiness Understanding

Pada fase ini ada empat tahap yang dilakukan, yaitu :

a. Pemahaman terhadap tujuan bisnis.

Meningkatkan dan mempertahankan jumlah konsumen erutama konsumen yang berpotensi untuk menjadi konsumen tetap (pelanggan).

b. Penilaian situasi (situation assessment).

CV. Karunia merupakan suatu perusahaan yang kegiatan utamanya sebagai distributor kosmetik . CV. Karunia belum melakukan pemanfaatan data pelanggan maupun data transaksi secara baik, bahkan data-data transaksi penjualan pada CV. Karunia dihapus dari server tanpa adanya back up data dengan alasan akan membebani server. Saat ini CV.Karunia telah menangani lebih dari 1000 transaksi penjualan kosmetik.

c. Menerjemahkan tujuan bisnis ke dalam tujuan data mining.

Customer segmentation dapat digunakan oleh pihak manajemen untuk menemukan segmensegmen konsumen yang bertujuan untuk Membangun profil dari konsumen (customer profiling) yang terkait dengan purchase history dan menentukan pemasaran yang tepat pada setiap segmen yang terbentuk.

2. Data Understanding

Pada proses ini akan dilakukan pemahaman terhadap kebutuhan data terkait dengan pencapaian tujuan dalam CRM dan data mining.

Penelitian ini dilakukan pada salah satu Distributor kosmetik di daerah Kabupaten Probolinggo. Obyek penelitian dalam kasus ini digunakan untuk melakukan segmentasi pelanggan pembeli produk yang tersimpan dalam database server penjualan di CV. Karunia . Data mining yang digunakan untuk segmentasi adalah dengan metode SOM. Data yang digunakan adalah data transaksi selama 5 tahun terakhir dengan format .rtf.

\section{Data Preparation}

Pada tahap ini struktur basis data akan dipersiapkan sehingga mempermudah proses mining. Proses preparation ini mencakup tiga hal utama yaitu:

a. Data Selection

Memilih data yang akan digunakan dalam proses data mining. Dalam proses ini dilakukan juga pemilihan atribut-atribut yang disesuaikan dengan proses data mining.

b. Data Preprocessing

Memastikan kualitas data yang telah dipilih pada tahap data selection, pada tahap ini masalah yang harus dihadapi adalah noisy data dan missing values. Proses pembersihan data (cleansing) dilakukan dengan melakukan metode-metode query sederhana untuk menemukan anomali-anomali data yang bisa saja masih terdapat pada sistem.

c. Data Transformation

Mengelompokkan atribut-atribut atau fieldyang telah terpilih menjadi 1 tabel dengan cara melakukan denormalisasi dari basis data OLTP

4. Pemodelan (modeling)

Metode yang digunakan yaitu metode SOM. Untuk menghitung data dalam penelitian ini akan menggunakan framework RapidMiner versi 5.2 sehingga akan ditemukan nilai akurat.

5. Evaluasi

Berdasarkan hasil clustering dengan metode Rapidminer versi 5.2 dilakukan evaluasi kluster yang terbentuk dan diselaraskan dengan tujuan penelitian yang dilakukan.

6. Strategi Pemasaran

Strategi pemasaran CV. Karunia didefinisikan dan diterapkan ke anggota dari setiap kelas yang terbentuk sebagai hasil clustering.

\subsection{Persiapan Data}

Data transaksi penjualan diperoleh dari CV. Karunia yang bertempat di probolinggo Jawa Timur. Data ini merupakan data penjualan yang kami dapatkan dari admin CV. Karunia yang berbentuk excel.

Tabel 2. Tabel Contoh Data Awal

\begin{tabular}{lllll}
\hline No & Faktur & Toko & DPP & Nil.Faktur \\
\hline 1 & 16075501 & $\begin{array}{l}\text { BC SMKN 1 } \\
\text { Probolinggo }\end{array}$ & 591.724 & 650.897 \\
\hline 2 & 16075502 & $\begin{array}{l}\text { Risda Toko, } \\
\text { Jln. Mastrip }\end{array}$ & 238.002 & 261.802 \\
\hline 3 & 16075503 & $\begin{array}{l}\text { Dewi Indah, } \\
\text { Wonoasih }\end{array}$ & 53.865 & 59.252 \\
\hline
\end{tabular}




\begin{tabular}{|c|c|c|c|c|}
\hline 4 & 16075504 & $\begin{array}{l}\text { Ansori H. } \\
\text { Toko, Pasar } \\
\text { Wonoasih }\end{array}$ & 132.513 & 145.764 \\
\hline 5 & 16075505 & $\begin{array}{l}\text { Stand 08, } \\
\text { Pasar } \\
\text { Wonoasih }\end{array}$ & 134.735 & 148.209 \\
\hline 6 & 16075506 & $\begin{array}{l}\text { Stand 05, } \\
\text { Pasar } \\
\text { Wonoasih }\end{array}$ & 198.570 & 218.427 \\
\hline 7 & 16075507 & $\begin{array}{l}\text { Dina, } \\
\text { Wonoasih }\end{array}$ & 812.181 & 893.399 \\
\hline 8 & 16075508 & $\begin{array}{l}\text { Dina, } \\
\text { Wonoasih }\end{array}$ & 136.848 & 150.533 \\
\hline 9 & 16075509 & $\begin{array}{l}\text { Zaki Toko, } \\
\text { Raya } \\
\text { Bantaran }\end{array}$ & 131.652 & 144.817 \\
\hline 10 & 16075510 & $\begin{array}{l}\text { Rahayu } \\
\text { Toko, Raya } \\
\text { Bantaran }\end{array}$ & 535.966 & 589.562 \\
\hline 11 & 16075511 & $\begin{array}{l}\text { Sanur } \\
\text { Toko, } \\
\text { Kareng } \\
\text { Kidul }\end{array}$ & 609.852 & 670.837 \\
\hline 12 & 16075512 & $\begin{array}{l}\text { Aisyah } \\
\text { Toko, Raya } \\
\text { Kropak }\end{array}$ & 517.116 & 568.828 \\
\hline 13 & 16075513 & $\begin{array}{l}\text { Khotijah } \\
\text { Toko, Raya } \\
\text { Bantaran }\end{array}$ & 95.401 & 104.941 \\
\hline 14 & 16075514 & $\begin{array}{l}\text { Elfan Toko, } \\
\text { Jln. } \\
\text { Tempuran }\end{array}$ & 251.031 & 276.134 \\
\hline 15 & 16075515 & $\begin{array}{l}\text { Nyata } \\
\text { Abadi Toko, } \\
\text { Jl. Mastrip }\end{array}$ & 593.099 & 652.409 \\
\hline 16 & 16075516 & $\begin{array}{l}\text { Indah Jaya, } \\
\text { Wonoasih }\end{array}$ & 164.294 & 180.723 \\
\hline 17 & 16075517 & $\begin{array}{l}\text { Sari Rasa } \\
\text { Toko, Jln. } \\
\text { Wahid }\end{array}$ & 515.778 & 567.356 \\
\hline 18 & 16075518 & $\begin{array}{l}\text { Citra Indah, } \\
\text { Jl. Wahid } \\
\text { Hasyim }\end{array}$ & 421.584 & 463.742 \\
\hline 19 & 16075520 & $\begin{array}{l}\text { Arip H. } \\
\text { Toko, Pasar } \\
\text { Bantaran }\end{array}$ & 35.273 & 38.800 \\
\hline 20 & 16075521 & $\begin{array}{l}\text { Antok Toko, } \\
\text { Pasar } \\
\text { Bantaran }\end{array}$ & 404.728 & 445.201 \\
\hline
\end{tabular}

\subsection{Pra Pengolahan Data}

Sebelum langsung dimasukan pada proses pengolahan data, terlebih dahulu dilakukan proses pra pengolahan data diantaranya pembersihan data konversi data dan normalisasi data.

\subsection{Pembersihan Data}

Proses pembersihan data ini dilakukan untuk membuang record yang tidak sesuai dengan kebutuhan contohnya adalah faktur, nama sales, ppn, yang nantikan akan digunakan dalam proses mining, mengendalikan data yang hilang dan melakukan validasi dari 30 setiap record terhadap duplikasi data. Data-data yang tidak konsisten mengandung noise dan banyak kekeliruan membuat hasil pengelompokkan data tidak akurat

Tabel 3. Tabel Pembersihan Data

\begin{tabular}{llll}
\hline No & Tgl & Kd Pelangan & Nil.Faktur \\
\hline 1 & $01 / 05 / 2018$ & Kd0001 & 650.897 \\
\hline 2 & $01 / 05 / 2018$ & Kd0002 & 261.802 \\
\hline 3 & $01 / 05 / 2018$ & Kd0003 & 59.252 \\
\hline 4 & $01 / 05 / 2018$ & Kd0004 & 145.764 \\
\hline 5 & $01 / 05 / 2018$ & Kd0005 & 148.209 \\
\hline 6 & $01 / 05 / 2018$ & Kd0006 & 218.427 \\
\hline 7 & $01 / 05 / 2018$ & Kd0007 & 893.399 \\
\hline 8 & $01 / 05 / 2018$ & Kd0007 & 150.533 \\
\hline 9 & $01 / 05 / 2018$ & Kd0008 & 144.817 \\
\hline 10 & $01 / 05 / 2018$ & Kd0009 & 589.562 \\
\hline 11 & $01 / 05 / 2018$ & Kd0010 & 670.837 \\
\hline 12 & $01 / 05 / 2018$ & Kd0011 & 568.828 \\
\hline 13 & $01 / 05 / 2018$ & Kd0012 & 104.941 \\
\hline 14 & $01 / 05 / 2018$ & Kd0013 & 276.134 \\
\hline 15 & $01 / 05 / 2018$ & Kd0014 & 652.409 \\
\hline 16 & $01 / 05 / 2018$ & Kd0015 & 180.723 \\
\hline 17 & $01 / 05 / 2018$ & Kd0016 & 567.356 \\
\hline 18 & $01 / 05 / 2018$ & Kd0017 & 463.742 \\
\hline 19 & $01 / 05 / 2018$ & Kd0018 & 38.800 \\
\hline & & & \\
\hline
\end{tabular}

\subsection{Penerapan Model RFM}

Pada tahap ini, dilakukan pemilihan atribut yang disesuaikan dengan kebutuhan kriteria model RFM, yaitu rentang waktu transaksi akhir pelanggan dengan periode tertentu, jumlah frekuensi transaksi yang dilakukan pelanggan selama periode yang sudah ditentukan, serta jumlah nominal transaksi untuk setiap pelanggan selama periode tertentu (Jamal \& Yanto, 2019). Berikut uraian mengenai atribut yang dibutuhkan untuk model RFM :

1. Kriteria R (recency) Membutuhkan atribut yang menunjukkan adanya rentang waktu transaksi terakhir pelanggan dengan periode tertentu, sehingga atribut yang dibutuhkan adalah atribut tanggal transaksi

2. Kriteria $F$ (frequency) Membutuhkan atribut yang merepresentasikan berapa kali pelanggan melakukan transaksi. 
Kriteria ini ini dapat dilihat dari berapa banyak pelanggan dengan nama yang sama muncul dalam data transaksi. Atribut yang dibutuhkan adalah atribut tanggal transaksi yang dihitung jumlahnya

3. Kriteria M (monetary) Membutuhkan atribut yang berhubungan dengan harga yang telah dihabiskan pelanggan selama melakukan transaksi, sehingga atribut yang dibutuhkan adalah atribut harga total yang harus dibayar pelanggan.

Jika katakanlah perusahaan memiliki sistem pengukuran berskala lima untuk masing-masing dimensi, maka yang bersangkutan dapat memetakan masingmasing pelanggannya berdasarkan data historis yang ada. Contoh skala yang dimaksud adalah sebagai berikut:

Tabel 4. Skala Recency, Frequency, Monetary

\begin{tabular}{|c|c|c|c|}
\hline RFM & Skala 3 & Skala 2 & Skala 1 \\
\hline Recency & $\begin{array}{l}1-7 \text { Hari } \\
\text { yang lalu }\end{array}$ & $\begin{array}{l}8-30 \text { hari } \\
\text { yang lalu }\end{array}$ & $\begin{array}{l}1-3 \\
\text { bulan } \\
\text { yang lalu }\end{array}$ \\
\hline Frequency & $\begin{array}{l}7 \mathrm{x} \\
\text { Transaksi } \\
\text { ke atas }\end{array}$ & $\begin{array}{l}3 \text { s/d } 6 \text { x } \\
\text { Transaksi }\end{array}$ & $1 \mathrm{~s} / \mathrm{d} 3 \mathrm{x}$ \\
\hline Monetary & $>=3 \mathrm{jt}$ & $\begin{array}{l}>=1 . \& \\
<=3 \mathrm{jt}\end{array}$ & $\begin{array}{l}\text { Di } \\
\text { bawah } 1 \\
\text { jt }\end{array}$ \\
\hline
\end{tabular}

Selanjutnya setelah melakukan proses persiapan data dan pra pengolahan data maka selanjutnya adalah pembentukan model RFM agar memudahkan dalam proses pengelompokan data dengan algoritma SOM, dibawah ini hasil dari model RFM yang sudah di bentuk berdasarkan data sebelumnya:

Tabel 5. Data Pelanggan dalam RFM

\begin{tabular}{llll}
\hline \multicolumn{5}{c}{ DATA RFM } \\
\hline Kode & Recency & Frequency & Monetary \\
& & & - \\
\hline C730 & 91 & 0 & - \\
\hline 1259 & 91 & 0 & - \\
\hline 2330 & 91 & 0 & 1.893 .296 \\
\hline 570 & 91 & 7 & - \\
\hline 0454 & 91 & 0 & - \\
\hline 5104 & 91 & 0 & 211.200 \\
\hline C839 & 91 & 1 & \\
\hline
\end{tabular}

\begin{tabular}{|c|c|c|c|}
\hline 5035 & 91 & 0 & - \\
\hline 7006 & 91 & 0 & - \\
\hline 00201 & 91 & 0 & - \\
\hline 0076 & 91 & 0 & _ \\
\hline C998 & 91 & 1 & 302.655 \\
\hline 0142 & 91 & 0 & - \\
\hline 0839 & 91 & 0 & - \\
\hline 0123 & 91 & 0 & - \\
\hline 0841 & 91 & 0 & - \\
\hline 13105 & 91 & 0 & - \\
\hline 1874 & 91 & 0 & - \\
\hline 2660 & 91 & 0 & - \\
\hline 1867 & 91 & 0 & - \\
\hline 2462 & 91 & 0 & - \\
\hline 1622 & 91 & 0 & - \\
\hline 470 & 91 & 0 & - \\
\hline 0118 & 91 & 0 & - \\
\hline 0942 & 91 & 0 & - \\
\hline 0092 & 91 & 0 & - \\
\hline 1180 & 91 & 0 & - \\
\hline 8775 & 91 & 0 & - \\
\hline 2701 & 91 & 1 & 698.927 \\
\hline 2177 & 91 & 0 & - \\
\hline
\end{tabular}

Tabel 6. Tabel RFM yang sudah dikonversi RFM INTERVAL

\begin{tabular}{cccc}
\hline NO & Recency & Frequency & Monetary \\
\hline C730 & 1 & 0 & 0 \\
\hline 1259 & 1 & 0 & 0 \\
\hline 2330 & 1 & 0 & 0 \\
\hline 570 & 1 & 3 & 2 \\
\hline 0454 & 1 & 0 & 0 \\
\hline 5104 & 1 & 0 & 0 \\
\hline C839 & 1 & 1 & 1 \\
\hline 5035 & 1 & 0 & 0 \\
\hline 7006 & 1 & 0 & 0 \\
\hline 00201 & 1 & 0 & 0 \\
\hline 0076 & 1 & 0 & 0 \\
\hline
\end{tabular}




\begin{tabular}{|c|c|c|c|}
\hline C998 & 1 & 1 & 1 \\
\hline 0142 & 1 & 0 & 0 \\
\hline 0839 & 1 & 0 & 0 \\
\hline 0123 & 1 & 0 & 0 \\
\hline 0841 & 1 & 0 & 0 \\
\hline 13105 & 1 & 0 & 0 \\
\hline 1874 & 1 & 0 & 0 \\
\hline 2660 & 1 & 0 & 0 \\
\hline 1867 & 1 & 0 & 0 \\
\hline 2462 & 1 & 0 & 0 \\
\hline 1622 & 1 & 0 & 0 \\
\hline 470 & 1 & 0 & 0 \\
\hline 0118 & 1 & 0 & 0 \\
\hline 0942 & 1 & 0 & 0 \\
\hline 0092 & 1 & 0 & 0 \\
\hline 1180 & 1 & 0 & 0 \\
\hline 8775 & 1 & 0 & 0 \\
\hline 2701 & 1 & 1 & 1 \\
\hline 2177 & 1 & 0 & 0 \\
\hline
\end{tabular}

Setelah dilakukan normalisasi data selanjutnya dilakukan pengelompokan data. Proses pengelompokan (clustering) pada penelitian ini mengunakan cara kerja algoritma SOM dengan untuk clustering dan memvisualisasikan pengelompokan. Pada proses pengelompokan SOM dimulai dengan pembentukan peta jaringan SOM dan pembentukan peta ini didasari dari data input yang menjadi masukan terhadap sistem yang dibuat.

Kemudian dilakukan proses pembelajaran dengan menggunakan beberapa kali iterasi untuk menghasilkan matrik bobot yang ideal. Matrik bobot ideal inilah yang nantinya dipakai untuk memetakan data input tersebut ke dalam kelompok data output. Proses pembelajaran SOM untuk membentuk peta jaringan dikenal dengan nama proses learning. Proses learning ini didasari dari jarak antara data input dengan matriks bobot, sehingga memunculkan parameter yang harus didefinisikan sebelum memulai proses training.

Jaringan SOM yang sudah diinisialisasi kemudian dilakukan proses training. Berikut proses pengelompokan data input menggunakan SOM pada masing-masing parameter.

\subsection{Pembahasan}

1. Proses Perhitungan Manual Algoritma SOM

2. Akan dilakukan clustering pada 8 buah data contoh

3. Parameter yang digunakan

a. Jumlah cluster 2

b. Jumlah iterasi pelatihan maksimal 6

c. Lajur pembelajaran 0.5

4. Inisialisasi bobot, dengan ukuran matrik dimensi berukuran 2x1, secara acak digunakan bobot awal sebagai berikut :

$$
W=\left[\begin{array}{lll}
3.02 & 2.1 & 6.99 \\
1.67 & 2.8 & 6.81
\end{array}\right]
$$

5. Contoh data dari 8 transaksi, dapat dilihat pada tabel 4.1

Tabel 6. Tabel Hasil RFM

\begin{tabular}{cccc} 
KODE & RECENCY & FREQUENCY & MONETARY \\
\hline 570 & 1 & 3 & 2 \\
\hline C839 & 1 & 1 & 1 \\
\hline C998 & 1 & 1 & 1 \\
\hline 2701 & 1 & 1 & 1 \\
\hline 43 & 1 & 1 & 1 \\
\hline 1833 & 1 & 2 & 3 \\
\hline 0040 & 1 & 1 & 1 \\
\hline C507 & 1 & 1 & 1 \\
\hline 1837 & 1 & 3 & 3 \\
\hline & & &
\end{tabular}

Untuk perhitungan manual menggunakan rumus: (Teuvo Kohonen, 1990)

$$
D(J)=\Sigma(\mathbf{W j i}-\mathbf{X i})^{\wedge} \mathbf{2}
$$

Sementara itu, untuk update bobot dengan rumus

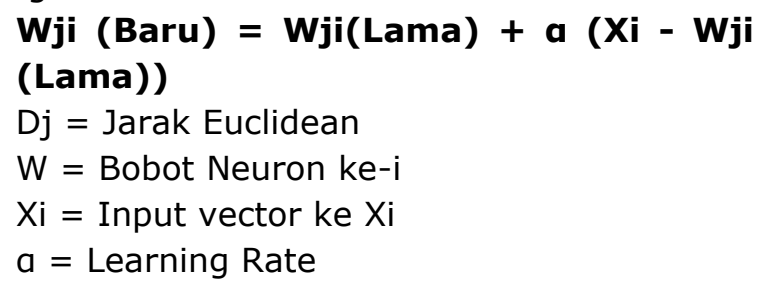

Bobot Awal : $W=\left[\begin{array}{lll}3.02 & 2.1 & 6.99 \\ 1.67 & 2.8 & 6.81\end{array}\right]$

Iterasi 1 ( kode pelanggan 570 )

Untuk data 1 [ $\left.\begin{array}{lll}1 & 3 & 2\end{array}\right]$, hitung jarak setiap neuron:

D1 $=(3.02-1)^{2}+(2.1-3)^{2}+(6.99-2)^{2}=29.79$ D2 $=(1.67-1)^{2}+(2.8-3)^{2}+(6.88-2)^{2}=24.18$

Jarak terdekat adalah neuron ke-2, maka neuron ke 2 diperbaharui bobotnya: 


$$
\begin{aligned}
& \text { Update Bobot }= \\
& \begin{aligned}
\text { W21 } & =1,57+0,5 *(1-1,57) \\
& =\mathbf{1 , 2 9} \\
\text { W22 } & =2,8+0,5 *(3-2,8) \\
& =\mathbf{2 , 9} \\
\text { W23 } & =6,88+0,5 *(2-6,88) \\
& =\mathbf{4 , 4 4}
\end{aligned}
\end{aligned}
$$

\begin{tabular}{|c|c|c|c|c|c|}
\hline $\begin{array}{l}\stackrel{0}{0} \\
\stackrel{0}{0}\end{array}$ & 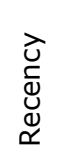 & $\begin{array}{l}\text { ปे } \\
\text { d } \\
\bar{J} \\
\bar{d} \\
\frac{1}{4}\end{array}$ & $\begin{array}{l}\frac{\lambda}{2} \\
\mathbb{2} \\
0 \\
0 \\
\Sigma \\
\Sigma \\
\Sigma\end{array}$ & 安 & $\begin{array}{l}\frac{n}{\pi} \\
\frac{\pi}{\mathbb{N}}\end{array}$ \\
\hline C730 & 1 & 0 & 0 & 1 & Cluster 3 \\
\hline 1259 & 1 & 0 & 0 & 1 & Cluster 3 \\
\hline 2330 & 1 & 0 & 0 & 1 & Cluster 3 \\
\hline 570 & 1 & 3 & 2 & 6 & Cluster 1 \\
\hline 454 & 1 & 0 & 0 & 1 & Cluster 3 \\
\hline 5104 & 1 & 0 & 0 & 1 & Cluster 3 \\
\hline C839 & 1 & 1 & 1 & 3 & Cluster 3 \\
\hline 5035 & 1 & 0 & 0 & 1 & Cluster 3 \\
\hline 7006 & 1 & 0 & 0 & 1 & Cluster 3 \\
\hline 201 & 1 & 0 & 0 & 1 & Cluster 3 \\
\hline 76 & 1 & 0 & 0 & 1 & Cluster 3 \\
\hline C998 & 1 & 1 & 1 & 3 & Cluster 3 \\
\hline 142 & 1 & 0 & 0 & 1 & Cluster 3 \\
\hline 839 & 1 & 0 & 0 & 1 & Cluster 3 \\
\hline 123 & 1 & 0 & 0 & 1 & Cluster 3 \\
\hline 841 & 1 & 0 & 0 & 1 & Cluster 3 \\
\hline 13105 & 1 & 0 & 0 & 1 & Cluster 3 \\
\hline 1874 & 1 & 0 & 0 & 1 & Cluster 3 \\
\hline 2660 & 1 & 0 & 0 & 1 & Cluster 3 \\
\hline 1867 & 1 & 0 & 0 & 1 & Cluster 3 \\
\hline 2462 & 1 & 0 & 0 & 1 & Cluster 3 \\
\hline 1622 & 1 & 0 & 0 & 1 & Cluster 3 \\
\hline 470 & 1 & 0 & 0 & 1 & Cluster 3 \\
\hline 118 & 1 & 0 & 0 & 1 & Cluster 3 \\
\hline 942 & 1 & 0 & 0 & 1 & Cluster 3 \\
\hline 92 & 1 & 0 & 0 & 1 & Cluster 3 \\
\hline 1180 & 1 & 0 & 0 & 1 & Cluster 3 \\
\hline 8775 & 1 & 0 & 0 & 1 & Cluster 3 \\
\hline 2701 & 1 & 1 & 1 & 3 & Cluster 3 \\
\hline 2177 & 1 & 0 & 0 & 1 & Cluster 3 \\
\hline
\end{tabular}

Bobot baru setelah diperbaharui :

$W=\left[\begin{array}{ccc}3.02 & 2.1 & 6.99 \\ \mathbf{1 . 2 9} & \mathbf{2 . 9} & \mathbf{4 . 4 4}\end{array}\right]$

Tabel 7. Hasil ketika sudah dicluster

\subsection{Perhitungan Statistica Trial Algoritma SOM}

1. Proses Clustering

Proses clustering pada penelitian ini menggunakan Self Organizing Map (SOM) adapun menu yang harus dipilih seperti gambar berikut:

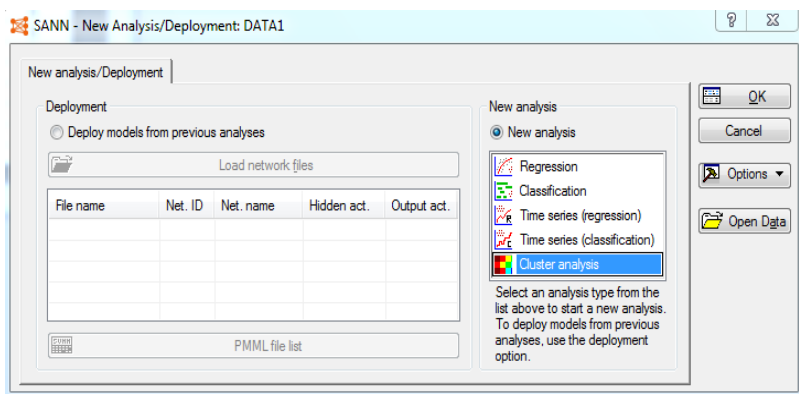

Gambar 3. Tampilan menu analisa clustering

2. Menu Variabel

Pilih menu variable untuk menentukan variable mana yang akan di lakukan proses clustering :

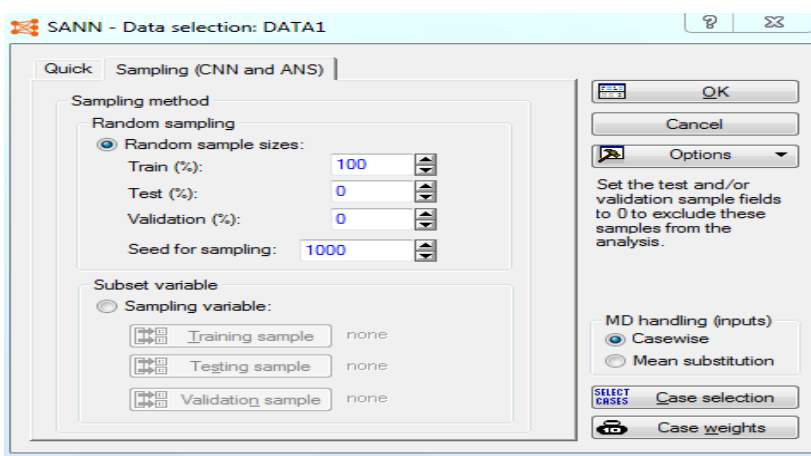

Gambar 4. Tampilan untuk Menentukan Variable

3. Menentukan Variabel

Untuk melakukan proses clustering, variabel yang akan dihitung harus dipilih. Untuk memudahkan menentukan variabel, centang pada check box pada "show oppropriate variable only"

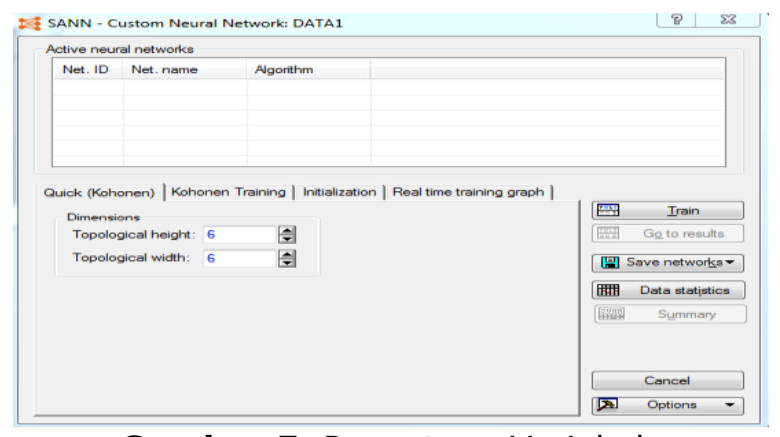

Gambar 5. Penentuan Variabel 


\section{Penentuan Sampel Random}

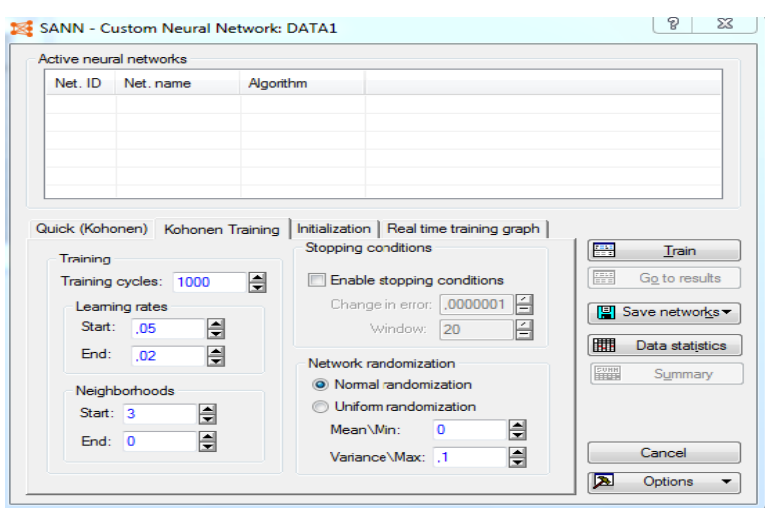

Gambar 6. Menentukan sampel random

5. Menentukan learning rate, iterasi

Learning rate bertujuan sebagai fungsi pembelajaran yang mana untuk memperbaharui bobot baru setian di temukan neuron pemenang dari data yang dihitung. Learning rate untuk pengujian ini dengan nilai yang berkurang dari 0,5 sampai 0,02 dan fungsi ketetanggan yang berkurang dari 3 sampai 0 . Sedangkan iterasi mempunyai fungsi sebagai perulangan untuk menghitung data yang di lakukan. Nilai iterasi di tentukan sebanyak 1000 kali, agar semakin banyak iterasi semakin akurat pengelompokkan yang di hasilkan.

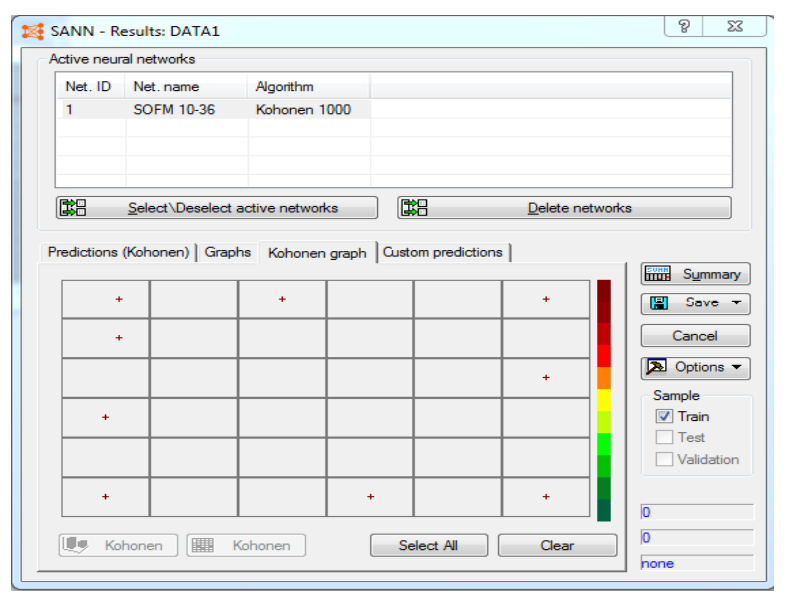

Gambar 7. Hasil cluster

Hasil pengelompokan bias dilihat pada table 4.2, dengan percobaan masukan ukuran dimensi 7x6 menghasilkan 42 cluster dan untuk cluster 11,19,20,21 serta 33 tidak memilikki anggota sama sekali yang bearti ukuran dimensi 7x6 tidak cocok untuk data ini.

\section{Penutup}

Berdasarkan hasil dari implementasi dan pen-gujian yang dilakukan peneliti, maka dapat di tarik kesimpulan sebagai berikut. Penelitian ini menghasilkan pemetaan pelanggan dengan metode SOM sebagai strategi pemasaran di CV Karunia. Peneliti mengucapkan terima kasih kepada CV Karunia yang telah memberikan kesempatan kepada penulis untuk penelitian segmentasi pelanggan.

\section{Daftar Pustaka}

Adiana, B. E., Soesanti, I., \& Permanasari, A. E. (2018). Analisis segmentasi pelanggan menggunakan kombinasi RFM model dan teknik clustering. Jurnal Terapan Teknologi Informasi, 2(1), 23-32.

Adji Magfirah, t. b. (2015). Menggunakan Data Mining Sebagai Customer Pada Bank Untuk Meningkatkan Customer Relationship management (CRM) dengan Metode Klasifikasi (Algoritma J-48, Zero$\mathrm{R}$ dan Naive Bayes). Prosiding SNST, 11.

Ahsan, N. F. (2010). Clustering Data Mahasiswa menggunakan SOM untuk menentukan Startegi promosi universitas kanjuruhan Malang. Ilkom 207, 15-17.

Asep Saefullah, M. (2106). Penerapan Metode Klasifikasi Data MIning Untuk prediksi Kelulusan Tepat waktu. STMIK Jurnal, 1417.

Chapman, P., Clinton, J., Kerber, R., Khabaza, T., Reinartz, T., Shearer, C., \& Wirth, R. (2000). CRISP-DM 1.0: Step-by-step data mining guide. SPSS inc, 9, 13.

Faizah, I., Rachma, N., \& Hufron, M. (2019). Pengaruh Celebrity Endorser terhadap Prurcahe Intention melalui Brand Image sebagai Variabel Intervening pada pengguna kosmetik Wardah di Toko Kurnia probolinggo. Jurnal Ilmiah Riset Manajemen, 8(03).

Istiana, M. I. (2016). Segemntasi Pelanggan Menggunakan Algoritma K-Means Sebagai Strategi Pemasaran pada LAROIBA Seluler. Jurnal 12903, 12-13.

Jamal, J., \& Yanto, D. (2019). Analisis RFM dan Algoritma K-Means untuk Clustering Loyalitas Customer. Energy, 9(1).

Karomi, M. A. (2016). Meningkatkan hasil Segmentasi Pelanggan Menggunakan Algoritma Fuzzy C-Means dan Outler Removal Clusstering. STMIK, 2-11. Februari 2007. 
Kuo, R. J., Ho, L. M., \& Hu, C. M. (2002). Integration of self-organizing feature map and K-means algorithm for market segmentation. Computers \& Operations Research, 29(11), 1475-1493.

Shin, H. W., \& Sohn, S. Y. (2004). Segmentation of stock trading customers according to potential value. Expert systems with applications, 27(1), 27-33.
Yuliana, R. (2013). Analisis strategi pemasaran pada produk sepeda motor matik berupa segmentasi, targeting, dan positioning serta pengaruhnya terhadap keputusan pembelian konsumen di Semarang. Jurnal STIE Semarang (Edisi Elektronik), 5(2), 79-92.

Zeniarja, J., \& Luthfiarta, A. (2015). Prediksi Churn dan Segmentasi Pelanggan Menggunakan Backpropagation Neural Network Berbasis Evolution Strategies. Techno. Com, 14(1), 49-54. 